\title{
Transient spontaneous remission in congenital MLL-AF10 rearranged acute myeloid leukemia presenting with cardiorespiratory failure and meconium ileus
}

Tobias Gyárfás ${ }^{1}$, Juergen Wintgens², Wolfgang Biskup ${ }^{2}$, Ilske Oschlies ${ }^{3}$, Wolfram Klapper ${ }^{3}$, Reiner Siebert ${ }^{4}$, Susanne Bens ${ }^{4}$, Claudia Haferlach ${ }^{5}$, Roland Meisel ${ }^{6}$, Michaela Kuhlen ${ }^{6 *}$ and Arndt Borkhardt ${ }^{6+}$

\begin{abstract}
Background: Neonatal leukemia is a rare disease with an estimated prevalence of about one to five in a million neonates. The majority being acute myeloid leukemia (AML), neonatal leukemia can present with a variety of symptoms including hyperleucocytosis, cytopenia, hepatosplenomegaly, and skin infiltrates. Chromosomal rearrangements including mixed lineage leukemia (MLL) translocations are common in neonatal AML.

Case presentation: A female neonate born at 34 weeks gestation presented with cardiorespiratory failure, hepatosplenomegaly, pancytopenia, and coagulopathy. She required intensive care treatment including mechanical ventilation, high-dose catecholamine therapy, and multiple transfusions. Small intestinal biopsy obtained during laparotomy for meconium ileus revealed an infiltrate by an undifferentiated monoblastic, MLL-rearranged leukemia. No other manifestations of leukemia could be detected. After spontaneous clinical remission, lasting 5 months without any specific treatment, the patient presented with leukemia cutis and full-blown monoblastic leukemia. MLL-AF10-rearranged AML could be re-diagnosed and successfully treated with chemotherapy and hematopoietic stem cell transplantation.

Conclusions: Our patient exhibited a unique manifestation of neonatal MLL-AF10 rearranged AML with cardiorespiratory failure and intestinal infiltration. It highlights the importance of leukemia in the differential diagnosis of neonatal distress, congenital hematological abnormalities, and skin lesions.
\end{abstract}

Keywords: Acute myeloid leukemia, Congenital, Meconium ileus, Cardiorespiratory failure, Spontaneous remission, Case report

\footnotetext{
* Correspondence: michaela.kuhlen@med.uni-duesseldorf.de

†Equal contributors

${ }^{6}$ Department of Pediatric Oncology, Hematology and Clinical Immunology,

University Children's Hospital, Medical Faculty, Heinrich Heine University,

Moorenstr. 5, 40225 Duesseldorf, Germany

Full list of author information is available at the end of the article
} 


\section{Correspondence/findings Background}

Acute myeloid leukemia (AML) accounts for about $18 \%$ of pediatric leukemias [1]. Disease onset during the neonatal period is extremely rare, with an estimated prevalence of one to five in a million neonates. The majority of neonatal leukemias are AML, and the most common type is monoblastic leukemia (FAB M5). Typical clinical features are skin infiltrations, hepatosplenomegaly, and cardiac failure. Prenatal symptoms including non-immune hydrops and polyhydramnios illustrate the in utero origin of the disease [2]. Like in infant leukemias, chromosomal rearrangements are regularly found in neonatal leukemias $[2,3]$ with chromosome $11 \mathrm{q} 23 / M L L$ rearrangements being by far the most common ones. [4].

\section{Case report}

We present the case of a 14-month-old girl from birth until today. Pregnancy was uneventful until 34 weeks gestation, when polyhydramnios, pathological cerebral Doppler flow, pleural effusions, and pathological cardiotocography led to performing a cesarean section. The girl was born pale, with no muscle tone, no spontaneous breathing, and bradycardia. The APGAR score was 2/6/7 at $1 / 5 / 10 \mathrm{~min}$. Persisting respiratory insufficiency required maximally invasive treatment including the administration of endotracheal surfactant, the use of a high-frequency oscillation ventilator and nitrogen monoxide to maintain sufficient oxygenation. Continuous dobutamine and adrenaline infusions were necessary due to severe circulatory deterioration starting immediately after birth. Echocardiogram revealed pulmonary hypertension and compromised right ventricular function. Massive hepatosplenomegaly was detectable on abdominal ultrasound.

An initial hemoglobin value of $6.3 \mathrm{~g} / \mathrm{dl}$ led to an emergency erythrocyte transfusion, and further erythrocyte transfusions were necessary in the first weeks of life. Multiple petechiae and suggilations were present at birth, thrombocytopenia and disseminated intravascular coagulopathy with unmeasurable thrombin time repeatedly required multiple thrombocyte concentrate and fresh-frozen plasma transfusions. An initial leukocyte count of $45.000 / \mu \mathrm{l}$ rapidly dropped to a minimum of $600 / \mu \mathrm{l}$.

The etiology of the clinical condition with cardiorespiratory failure, pancytopenia, and disseminated intravascular coagulopathy together with skin hemorrhages and hepatosplenomegaly was at first elusive. Ganciclovir was initiated for suspected cytomegalovirus infection but withdrawn following negative results. Given the possibility of neonatal sepsis, various antibiotics and fluconazole were administered, but inflammatory values did not markedly increase and microbiological cultures and extensive viral PCR studies yielded exclusively negative results. Peripheral blood smears from the fourth day of life revealed immature monocytic cells, and bone marrow puncture was found unrepresentative without evidence of blastic cells. Additional flow cytometry was unremarkable. Genetic predisposition for hemophagocytic lymphohistiocytosis was excluded.

The girl's clinical condition remained highly instable, when on the tenth day of life the assessment of acute abdomen required explorative laparotomy. During surgery, a meconium ileus was found that could only be resolved by establishment of an ileostomy. Because of a massively distended abdomen, abdominal closure could only be realized by placement of a patch. Buccal mucosa and ileum biopsies were undertaken to exclude neonatal hemochromatosis.

Unexpectedly, pathological examination revealed diffuse submucosal infiltration by polymorphous, atypical cells suspicious of Langerhans cell histiocytosis (LCH). Single-shot treatment with vincristine $(0.05 \mathrm{mg} / \mathrm{kg})$ and prednisolone $(1.5 \mathrm{mg} / \mathrm{kg} / \mathrm{d})$ for suspected $\mathrm{LCH}$ was immediately commenced. Five days later, the $\mathrm{LCH}$ diagnosis was rejected by reference pathology evaluation and reclassified as completely undifferentiated blastic transmural infiltration with diffuse growth pattern, positive staining for CD68, partial expression of S100, negative staining for langerin, lysozyme, CD1a, myeloperoxidase, CD34, and CD30, and an increased proliferation rate of 80 \% (MIB1) (Fig. 1).

To further classify the blastic infiltration, additional immuno-histochemical staining was performed and revealed partial expression of CD163, negativity for CD56, CD117, CD3, CD79a, desmin, NB84, pan-cytokeratin, synaptophysin, and $\mathrm{TdT}$, and preserved nuclear expression of INI1, thus being consistent with an undifferentiated leukemia with partial monoblastic differentiation. Further, a chromosomal breakpoint at the mixed lineage leukemia $(M L L)$ locus 11q23 could be detected by fluorescence in situ hybridization (FISH, LSI MLL Dual Color, Break Apart Probe, Abbott) substantiating the diagnosis of an undifferentiated, $M L L$ positive leukemia. Two subsequent bone marrow punctures at the age of 3 and 5 weeks did not show any signs of leukemia, and no $M L L$ rearrangement could be detected by FISH (Table 1).

Subsequently, leukocyte, erythrocyte, and thrombocyte counts recovered spontaneously, accompanied by gradual clinical improvement including complete weaning from ventilator support and reversal of ileostomy. The patient was discharged at 6 weeks of age and a weight of $2900 \mathrm{~g}$ in excellent clinical condition.

Subsequent clinical follow-up displayed regular weight gain (weight at birth $3000 \mathrm{~g}$, at the age of 6 weeks $2900 \mathrm{~g}$, at 3 months $4300 \mathrm{~g}$ ) and development and routine hematological controls remained unremarkable. 


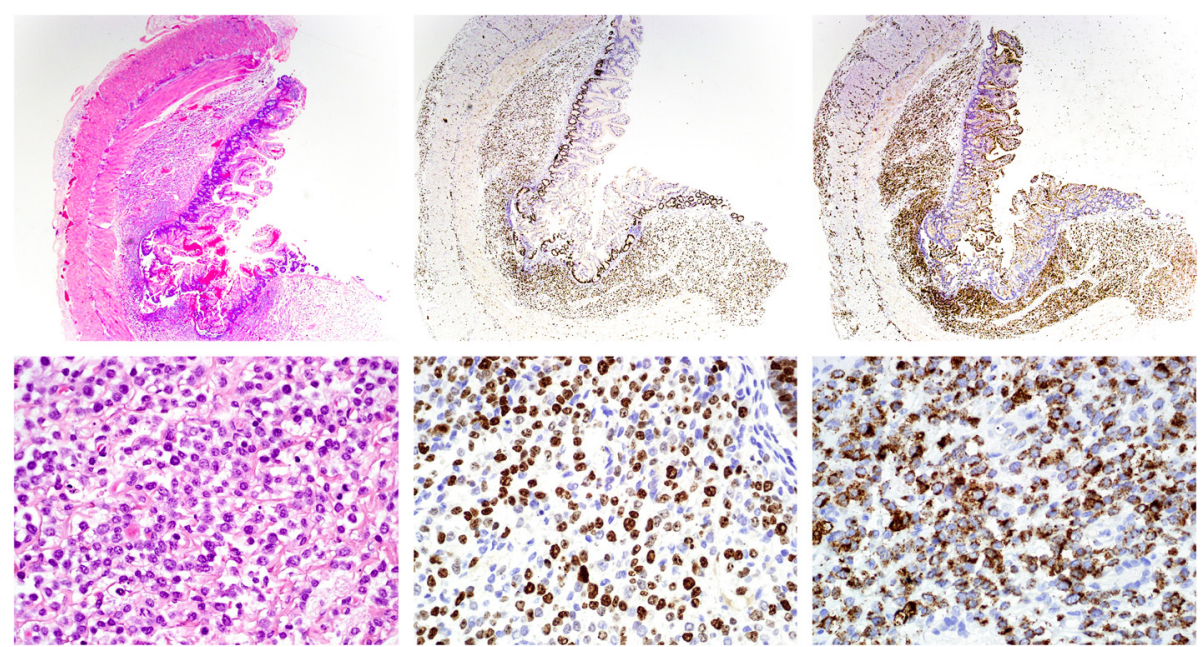

Fig. 1 Submucosal infiltrate of polymorphic, atypical cells in the terminal ileum. Top row: $\times 25$ magnification, bottom row: $\times 400$ magnification. Left: hematoxylin and eosin (H\&E) stain. Middle: KI67 staining shows a proliferation rate of $80 \%$. Right: the majority of cells display positive staining for the monocyctic marker CD68. A clonal MLL breakpoint in 11q23 was detected by FISH on paraffin embedded tissue-slides in the cells of the intestinal infiltrate. The population was classified as an extramedullary manifestation of monoblastic acute myeloid leukemia (AML FAB M5)

Five months later, while on treatment for hemangioma with propranolol, suspicious, blue-berry muffin-like skin lesions were noted on clinical examination. Leukocyte count was $28.500 / \mu \mathrm{l}$, and thrombocyte and erythrocyte counts were normal. Monoblastic leukemia (AML FAB M5) was diagnosed from peripheral blood and bone marrow (Fig. 2). An MLL-AF10 fusion transcript was detected by real-time and nested PCR. Retrospective analyses (by nested PCR) at the time point, when bone marrow sampled in the third week of life was $M L L$ rearrangement-negative by FISH, showed that the $M L L-$ AF10 fusion transcript was already detectable back then, 4 months prior to the definitive diagnosis of AML in the bone marrow (Table 1).

Table 1 Results of molecular studies on MLL rearrangement

\begin{tabular}{|c|c|c|c|c|}
\hline Sample type & $\begin{array}{l}\text { Obtained } \\
\text { at age }\end{array}$ & Method & Analysis & Result \\
\hline Ileum biopsy & 10 days & $\mathrm{FISH}$ & $\begin{array}{l}M L L \\
\text { rearrangement }\end{array}$ & Positive \\
\hline \multirow[t]{2}{*}{ Bone marrow } & 3 weeks & $\mathrm{FISH}$ & $\begin{array}{l}\text { MLL } \\
\text { rearrangement }\end{array}$ & Not feasible \\
\hline & & Nested PCR & MLL-AF10 & $\begin{array}{l}\text { Positive } \\
\text { (in retrospect) }\end{array}$ \\
\hline \multirow[t]{2}{*}{ Bone marrow } & 5 weeks & $\mathrm{FISH}$ & $\begin{array}{l}\text { MLL } \\
\text { rearrangement }\end{array}$ & Negative \\
\hline & & Nested PCR & MLL-AF10 & $\begin{array}{l}\text { Positive } \\
\text { (in retrospect) }\end{array}$ \\
\hline \multirow[t]{2}{*}{$\begin{array}{l}\text { Peripheral } \\
\text { blood }\end{array}$} & 5 months & $\mathrm{FISH}$ & $\begin{array}{l}\text { MLL } \\
\text { rearrangement }\end{array}$ & Positive \\
\hline & & RT-PCR ${ }^{a}$ & MLL-AF10 & Positive \\
\hline Bone marrow & 5 months & RT-PCR & MLL-AF10 & Positive \\
\hline
\end{tabular}

${ }^{a}$ Quantitative real time PCR
Chemotherapy was initiated according to the German AML-BFM 2012 study protocol [5]. Due to the $M L L$ AF10 rearrangement, the patient was classified as "high risk" and consequently qualified for hematopoietic stem cell transplantation (hSCT). The patient received one block of induction and two blocks of consolidation chemotherapy. Subsequently, the patient underwent hSCT from an unrelated, HLA-matched donor. The conditioning regimen consisted of busilvex, cyclophosphamide, melphalan, and anti-thymocyte globuline (ATG). Cyclosporin A and methotrexate were administered as prophylaxis against Graft versus Host Disease (GvHD). Leukocyte engraftment was detected at day 19, granulocyte engraftment at day 23 post transplantation. Chemotherapy and stem cell transplantation were well tolerated under supportive care. The girl was discharged at day +60 . Apart from partial compromise of renal function, no significant complications occurred. Until now, the patient is well, relapse-free, and showing no signs of GvHD 9 months after transplantation. Donor chimerism is $100 \%$.

\section{Discussion}

Neonatal leukemia is extremely rare. It accounts for about $1 \%$ of pediatric leukemias and has an estimated prevalence of one to five in a million neonates. The disease was already known in the early twentieth century [6]. Neonatal AML shows similarities to transient myeloproliferative disorder (TMD), an abnormal proliferation of myeloid blasts observed in Down's syndrome that usually resolves without therapy [7]. A few cases with spontaneous remission, which in one case was transient, mimicking TMD of Down syndrome, have been described in neonates with 


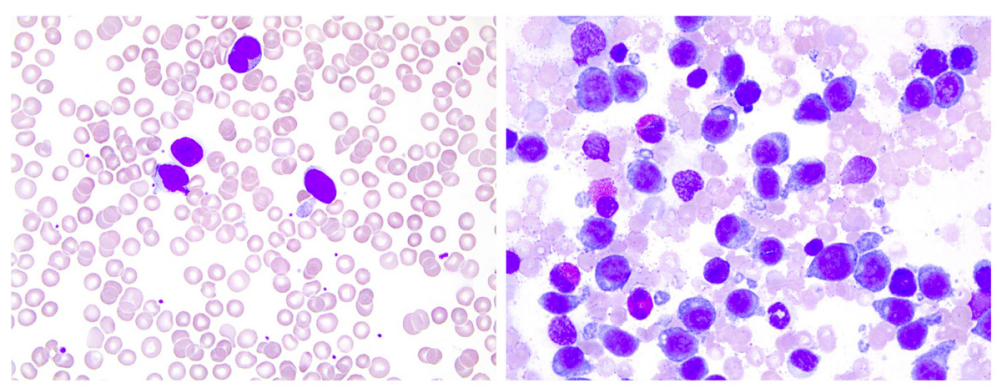

Fig. 2 Monoblastic leukemia (AML FAB M5) (x63 magnification) diagnosed from peripheral blood (left) and bone marrow (right) at the age of 5 months

normal karyotypes $[2,8,9]$. Isolated leukemia cutis has also been described to disappear spontaneously $[10,11]$. However, to the best of our knowledge, no case of a preterm baby with persistent pulmonary hypertension (PPHN) and cardiorespiratory failure requiring NO-based artificial ventilation and high-dose catecholamines could successfully be rescued by combined efforts of intensive care, chemotherapy, and stem cell transplantation.

The clinical picture of neonatal leukemia is variable. Common symptoms include leukocytosis, cytopenia, hepatosplenomegaly, and skin infiltrations. The latter are known as leukemia cutis, appear in about $60 \%$, and are the first symptom in about one half of neonatal leukemia cases. Leukemia cutis, presenting as firm nodules, papules or plaques of red, blue or purple color, is a differential diagnosis of the so-called blueberry muffin baby. This syndrome has a diversified differential, ranging from hemato-oncological disorders like Langerhans cell histiocytosis, neuroblastoma, or rhabdomyosarcoma to infectious diseases like rubella, cytomegalovirus infection, or toxoplasmosis to hemolytic disease and blue rubber bleb nevus syndrome $[12,13]$. Leukemia cutis has been described as an exclusive manifestation of AML without bone marrow disease [14], as well as appearing prior to or simultaneously with bone marrow involvement $[13,15]$. Our patient presented with severe bruising at birth, probably due to thrombocytopenia and coagulopathy. Months later after presumed relapse of the so far not unequivocally diagnosed AML, she primarily presented with skin infiltrations.

As a hematological malignancy, leukemia is essentially a distributed disease, but primary presentation as extramedullary infiltration, also called myeloid sarcoma, is a rarity in AML. Pediatric myeloid sarcoma has a prevalence of about 0.7 in one million children and can progress to AML $[16,17]$. Infiltration of the gastrointestinal tract, including the ileum, has been reported in AML $[18,19]$. In our patient, acute meconium ileus appeared on the tenth day of life. An extensive infiltration of monoblasts was found as the probable cause of the mechanical ileus. To our knowledge, such a condition has also not yet been described in neonatal leukemia.
Chromosome $11 \mathrm{q} 23$ rearrangements involving the $M L L$ gene locus are common in infant leukemia; they are the most frequent finding in neonatal AML [2]. Specifically, our patient had an MLL-AF10 fusion transcript, which is rather rarely found among the large variety of the various $M L L$ rearrangements [20]. In the AML-BFM 2012 protocol, $M L L-A F 10$ positive patients are considered "high risk" and recruited to a treatment protocol including hSCT. In our patient, a $M L L$ rearrangement was first diagnosed from the intestinal infiltrate found in the terminal ileum and a $M L L-A F 10$ fusion transcript was first detected at 5 months of age. In retrospect, its presence could then be verified from the bone marrow obtained at the age of 3 and 5 weeks by a sensitive PCR assay.

As from the first days of life there is no more material available, it remains somehow unclear of what extent the leukemia initially presented and whether the cytopenia was due to bone marrow involvement or whether it was associated to cytokine release and/or coagulopathy. In the following weeks, the clinical condition improved and no signs of leukemia could be detected. It cannot be ruled out with certainty that regression of the leukemia was not spontaneous but caused by a single dose of vincristine and prednisolone treatment; however, given the prolonged recovery, the latter seems unlikely. Thus, other reasons for spontaneous regression of this aggressive type of leukemia, such as infection or disease related cytokine release, should be considered.

Taken together, these findings indicate that our patient had a neonatal, MLL-AF10 positive AML with spontaneous transient regression that later reappeared as leukemia cutis and bone marrow disease.

\section{Conclusion}

We present a unique manifestation of neonatal $M L L$ AF10 positive AML with cardiorespiratory failure at birth, intestinal infiltration, and skin involvement. After a transient spontaneous regression, the patient was successfully treated by chemotherapy and hSCT and is alive and well. 


\section{Abbreviations}

AF10, ALL1-fused gene from chromosome 10 protein; AML, acute myeloid leukemia; ATG, anti-thymocyte globuline; BFM, Berlin Frankfurt Münster; CD, cluster of differentiation; FAB, French-American-British; FISH, fluorescence in situ hybridization; GvHD, Graft versus Host Disease; hSCT, hematopoietic stem cell transplantation; LCH, Langerhans cell histiocytosis; MLL, mixed lineage leukemia; PCR, polymerase chain reaction; PPNH, persistent pulmonary hypertension; RT$P C R$, real-time PCR; TMD, transient myeloproliferative disorder

\section{Funding}

No funding

\section{Authors' contributions}

TG first drafted the manuscript. JW and WB cared for the preterm and critically reviewed the manuscript for important intellectual content. WK and $\mathrm{IO}$ performed the pathological analysis. $\mathrm{RS}, \mathrm{SB}$, and $\mathrm{CH}$ performed the molecular analyses. RM critically revised the manuscript for important intellectual content. MK and $\mathrm{AB}$ supervised the project and reviewed and revised the manuscript for important intellectual content. All authors approved the final manuscript as submitted.

\section{Competing interests}

The authors declare that they have no competing interests.

\section{Consent for publication}

Written informed consent for the publication was given by both parents.

\section{Author details}

${ }^{1}$ Medical Faculty, Department of General Pediatrics, Neonatology and Pediatric Cardiology, Centre for Child and Adolescent Health, University of Duesseldorf, Duesseldorf, Germany. ${ }^{2}$ Department of Neonatology, Staedtische Kliniken Moenchengladbach, Elisabeth Krankenhaus Rheydt, Rheydt, Germany. ${ }^{3}$ Department of Pathology, Christian-Albrechts-University Kiel, Kiel, Germany. ${ }^{4}$ Institute of Human Genetics,

Christian-Albrechts-University Kiel, Kiel, Germany. ${ }^{5} \mathrm{MLL}$ Munich Leukemia Laboratory, Munich, Germany. ${ }^{6}$ Department of Pediatric Oncology, Hematology and Clinical Immunology, University Children's Hospital, Medical Faculty, Heinrich Heine University, Moorenstr. 5, 40225 Duesseldorf, Germany.

Received: 27 March 2016 Accepted: 3 August 2016

Published online: 29 August 2016

\section{References}

1. Puumala SE, Ross JA, Aplenc R, Spector LG (2013) Epidemiology of childhood acute myeloid leukemia. Pediatric Blood \& Cancer 60(5):728-733. doi:10.1002/pbc.24464

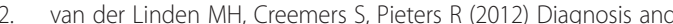
management of neonatal leukaemia. Seminars in Fetal \& Neonatal Medicine 17(4):192-195. doi:10.1016/j.siny.2012.03.003

3. Sansone R, Negri D (1992) Cytogenetic features of neonatal leukemias. Cancer Genetics and Cytogenetics 63(1):56-61

4. Slany RK (2009) The molecular biology of mixed lineage leukemia. Haematologica 94(7):984-993. doi:10.3324/haematol.2008.002436

5. Creutzig U, Zimmermann M, Dworzak MN, Ritter J, Schellong G, Reinhardt D (2013) Development of a curative treatment within the AML-BFM studies. Klinische Padiatrie 225(Suppl 1):S79-86. doi:10.1055/s-0033-1337968

6. Bernhard WG, Gore I, Kilby RA (1951) Congenital leukemia. Blood 6(11):990-1001

7. Karandikar NJ, Aquino DB, McKenna RW, Kroft SH (2001) Transient myeloproliferative disorder and acute myeloid leukemia in Down syndrome. An immunophenotypic analysis. American Journal of Clinical Pathology 116(2):204-210. doi:10.1309/XREF-C9T2-6U0A-4EDT

8. Isaacs H Jr (2003) Fetal and neonatal leukemia. Journal of Pediatric Hematology/Oncology 25(5):348-361

9. Chu JY, O'Connor DM, Gale GB, Silberstein MJ (1983) Congenital leukemia: two transient regressions without treatment in one patient. Pediatrics 71(2):277-279

10. D'Orazio JA, Pulliam JF, Moscow JA (2008) Spontaneous resolution of a single lesion of myeloid leukemia cutis in an infant: case report and discussion. Pediatric Hematology and Oncology 25(5):457-468. doi:10.1080/ 08880010802104494
11. Gottesfeld E, Silverman RA, Coccia PF, Jacobs G, Zaim MT (1989) Transient blueberry muffin appearance of a newborn with congenital monoblastic leukemia. Journal of the American Academy of Dermatology 21(2 Pt 2): 347-351

12. Fender AB, Gust A, Wang N, Scott GA, Mercurio MG (2008) Congenital leukemia cutis. Pediatr Dermatol 25(1):34-37. doi:10.1111/j.1525-1470.2007.00578.x

13. Isaacs H Jr (2011) Cutaneous metastases in neonates: a review. Pediatr Dermatol 28(2):85-93. doi:10.1111/j.1525-1470.2011.01372.x

14. Torrelo A, Madero L, Mediero IG, Bano A, Zambrano A (2004) Aleukemic congenital leukemia cutis. Pediatr Dermatol 21(4):458-461. doi:10.1111/j. 0736-8046.2004.21408.x

15. Zhang $\mathrm{H}_{\text {, }}$ Zane LT, Braun BS, Maize J Jr, Zoger S, Loh ML (2006) Congenital leukemia cutis with subsequent development of leukemia. Journal of the American Academy of Dermatology 54(2 Suppl):S22-27. doi:10.1016/j.jaad. 2005.04.038

16. Antic D, Elezovic I, Bogdanovic A, Vukovic NS, Pavlovic A, Jovanovic MP, Jakovic L, Kraguljac N (2010) Isolated myeloid sarcoma of the gastrointestinal tract. Internal Medicine 49(9):853-856

17. Reinhardt D, Creutzig U (2002) Isolated myelosarcoma in children-update and review. Leukemia \& Lymphoma 43(3):565-574. doi:10.1080/ 10428190290012056

18. Cornes JS, Jones TG (1962) Leukaemic lesions of the gastrointestinal tract. Journal of Clinical Pathology 15:305-313

19. Domingo-Domenech E, Boque C, Narvaez JA, Romagosa V, Domingo-Claros A, Granena A (2000) Acute monocytic leukemia in the adult presenting with associated extramedullary gastric infiltration and ascites. Haematologica 85(8):875-877

20. Meyer C, Hofmann J, Burmeister T, Groger D, Park TS, Emerenciano M, Pombo de Oliveira M, Renneville A, Villarese P, Macintyre E, Cave H, Clappier E, Mass-Malo K, Zuna J, Trka J, De Braekeleer E, De Braekeleer M, Oh SH, Tsaur G, Fechina L, van der Velden VH, van Dongen JJ, Delabesse E, Binato R, Silva ML, Kustanovich A, Aleinikova O, Harris MH, Lund-Aho T, Juvonen $\mathrm{V}$, Heidenreich $\mathrm{O}$, Vormoor J, Choi WW, Jarosova M, Kolenova A, Bueno C, Menendez P, Wehner S, Eckert C, Talmant P, Tondeur S, Lippert E, Launay E, Henry C, Ballerini P, Lapillone H, Callanan MB, Cayuela JM, Herbaux C, Cazzaniga G, Kakadiya PM, Bohlander S, Ahlmann M, Choi JR, Gameiro P, Lee DS, Krauter J, Cornillet-Lefebvre P, Te Kronnie G, Schafer BW, Kubetzko S, Alonso CN, zur Stadt U, Sutton R, Venn NC, Izraeli S, Trakhtenbrot L, Madsen HO, Archer P, Hancock J, Cerveira N, Teixeira MR, Lo Nigro L, Moricke A, Stanulla M, Schrappe M, Sedek L, Szczepanski T, Zwaan CM, Coenen EA, van den Heuvel-Eibrink MM, Strehl S, Dworzak M, Panzer-Grumayer R, Dingermann T, Klingebiel T, Marschalek R (2013) The MLL recombinome of acute leukemias in 2013. Leukemia 27(11):2165-2176. doi:10.1038/leu.2013.135

\section{Submit your manuscript to a SpringerOpen ${ }^{\circ}$ journal and benefit from:}

- Convenient online submission

- Rigorous peer review

- Immediate publication on acceptance

- Open access: articles freely available online

- High visibility within the field

- Retaining the copyright to your article

Submit your next manuscript at $>$ springeropen.com 